\title{
Endogenous Cytokinins Dynamics in Mycelial Biomass of Basidiomycetes at Different Stages of Cultivation
}

\author{
Vedenicheva NP, Al Maali GA, Mykhaylova OB, Lomberg ML, \\ Bisko NA, Shcherbatiuk MM and Kosakivska IV* \\ Department of Phytohormonology, M.G. Kholodny Institute of Botany, National \\ Academy of Sciences of Ukraine, Ukraine
}

\section{Research Article \\ Volume 3 Issue 2}

Received Date: March 05, 2018

Published Date: March 26, 2018

*Corresponding author: Iryna Kosakivska, 2, Tereshchenkivska Str., Kyiv, 01601, Ukraine, Tel: +38(044)2341064;

E-mail: irynakosakivska@gmail.com

\section{Abstract}

The study of cytokininis content dynamics in micelial biomass of two Basidiomycetes species (Hericium coralloides, strain 2332, Fomitopsis officinalis, strain 5004) at the different stages of cultivation was carried out by HPLC-MS. The maximum content of trans-zeatin, trans-zeatin riboside, isopentenyladenosine and isopentenyladenine in $H$. coralloides 2332 was shown to take place at the period of the most intensive growth whereas the development inhibition is accompanied by a decrease in free cytokinins levels. The free cytokinins levels in F. officinalis 5004 raised when no sharp fluctuations in growth parameters of mycelial biomass occurred. Changes in all cytokinins content during mycelia biomass growth were specific and indicate the involvement of these phytohormones in the regulation of growth and development of the studied mushrooms species.

Keywords: Basidiomycetes; Mycelial Biomass; Cytokinins; Growth

Abbreviations: HPLC-MS: High Performance Liquid Chromatography Coupled with Masspectrometry; iP: Isopentenyladenine; $\mathrm{iPa}$ Isopentenyladenosine, $\mathrm{t}-\mathrm{Z}$ : Trans-zeatin; ZOG: Zeatin-O-glucoside; t-ZR: transzeatin riboside

\section{Introduction}

Cytokinins are a group of phytohormones, which control cell division, sink/source relationships and nutrient uptake in plant tissues, stimulate the production and activity of shoot meristems, and inhibit root growth and branching, retard leaf senescence, affect seed germination and formation of responses to stresses and other aspects of plant development [1]. The bulk of information concerning a cytokinin regulatory action has been obtained for plants. The development of molecular-genetic methods allowed to make a great progress in understanding the cytokinin biosynthetic and metabolic pathways, mechanisms of cytokinin perception and transport [2]. In the higher vascular plants, cytokinins act as signaling molecules that transfer information regarding various environmental factors to the cell genome and thus trigger appropriate responses as protein synthesis [2]. Cytokinins occur both in a free and tRNA-bound form in the most diverse groups of organisms: bacteria, lower and higher plants, fungi, nematodes, insects, humans. It is assumed that evolutionarily, these molecules primary functions were to improve protein translation in ribosomes because that caused the modification of anticodon 3 -end in specific tRNAs [3]. It appears that phytohormones began to perform a regulating and signaling function only in land plants while in less evolutionary developed organisms and especially in representatives of other kingdoms they are just metabolic products [4]. Experimental data to prove such possibility is not enough. 


\section{International Journal of Biochemistry \& Physiology}

Fungi form a special kingdom of living creatures, which possess both plant and animal features in their cell structure and metabolism. Cytokinins were detected in many Fungi species [5]. The involvement of these hormones in plant-pathogen interaction under fungal infections has been elucidated enough whereas their functions in growth and development regulation of Fungi themselves are yet unknown [6-8]. There were some reports about exogenous cytokinins influence on both micro- and macromycetes growth. In particular, positive effects of kinetin on the enhancement of mycelia growth and production of chitosan were observed in Kluyveromyces fragilis, Rhizopus oryzae and Mucor indicus [9-11]. Kinetin also had a significant effect on the cap size and style length of Pleurotus ostreatus [12]. The introduction of kinetin to a culture medium increased protein biomass and content in Pleurotus sajor-caju and Agaricus campestris [13,14]. A mycelium growth decrease in Amanita muscaria following aluminum treatment correlated with some reduction in the cytokinin total content [15]. These studies show that cytokinins might be involved in Fungi development regulation although another way of their action is not excluded. Much less is known about endogenous cytokinins behavior in Fungi, especially in macromycetes. Differences in hormone levels among more than 20 forest fungi species were detected, but the developmental stages at which the fruiting bodies were sampled and their exact age were not determined $[16,17]$. Changes in cytokinins content were estimated using bioassays during Lentinus tigrinus cultivation: the maximum in cytokinins activity was reached in a young vegetative mycelium, it decreased when fruiting bodies were formed and when they were growing [18].

Obviously, cytokinins have a high potential for the improvement of fungal productivity in culture that is very important because these organisms produce not only a high-quality protein product but also biologically active substances due to which they have valuable medical properties [19]. However, a limited number of publications on cytokinins in macromycetes does not answer the question about these phytohormones role in Fungi growth and development control. Thus, the aim of current study was to compare the growth characteristics of mycelial biomass of two Basidiomycetes species - Hericium coralloides and Fomitopsis officinalis - cultivated in vitro and the dynamics of endogenous cytokinins.

\section{Materials and Methods}

\section{Biological Material}

Two Basidiomycetes species were studied: Hericium coralloides (Scop.) Pers. (Figure 1) and Fomitopsis officinalis (Vill.: Fr.) Kotl. et Pouzar (Figure 2).
Fungi strains (H. coralloides strain 2332 and $F$. officinalis strain 5004) were cultivated in $250 \mathrm{ml}$ Erlenmeyer flasks with $50 \mathrm{ml}$ liquid medium in stationary conditions $\left(26 \pm 1^{\circ} \mathrm{C}\right)$ during 21 days (H. coralloides) and 40 days (F. officinalis) in darkness. Inoculation with physiologically active mycelium in proportion of $10 \%$ to total volume was carried out in accordance with the method developed for Basidiomycetes [20]. Microbiological control of nutrient medium and seeding material purity was fulfilled before inoculation. For cultivation of mycelial biomass the following liquid nutrient medium was used: glucose 30.0 g/l; $\mathrm{NH}_{4} \mathrm{NO}_{3}-3.5 \mathrm{~g} / \mathrm{l} ; \mathrm{KCl}-0.5 \mathrm{~g} / \mathrm{l} ; \mathrm{K}_{2} \mathrm{HPO}_{4}-1.0$ $\mathrm{g} / \mathrm{l} ; \mathrm{MgSO}_{4} \cdot 7 \mathrm{H}_{2} \mathrm{O}-0.5 \mathrm{~g} / \mathrm{l}$; beer wort $\left(15^{\circ}\right.$ in accordance with Baling method) - $115 \mathrm{ml} ; \mathrm{H}_{2} \mathrm{O}-1 \mathrm{l}, \mathrm{pH}-5.0$. Mediums acidity was maintained at necessary $\mathrm{pH}$ levels by $1 \mathrm{~N} \mathrm{KOH}$ and $1 \mathrm{~N} \mathrm{HCl}$ solutions addition. The order of cultivation: strain mycelial culture on agar medium in vial $\rightarrow$ strain mycelial culture on agar medium in Petri dish (Figure 3) $\rightarrow$ strain mycelial culture in liquid nutrient medium in flask with bumper $\rightarrow$ shaking $\rightarrow$ strain mycelial culture in liquid nutrient medium in laboratory bottle (Figure 4).

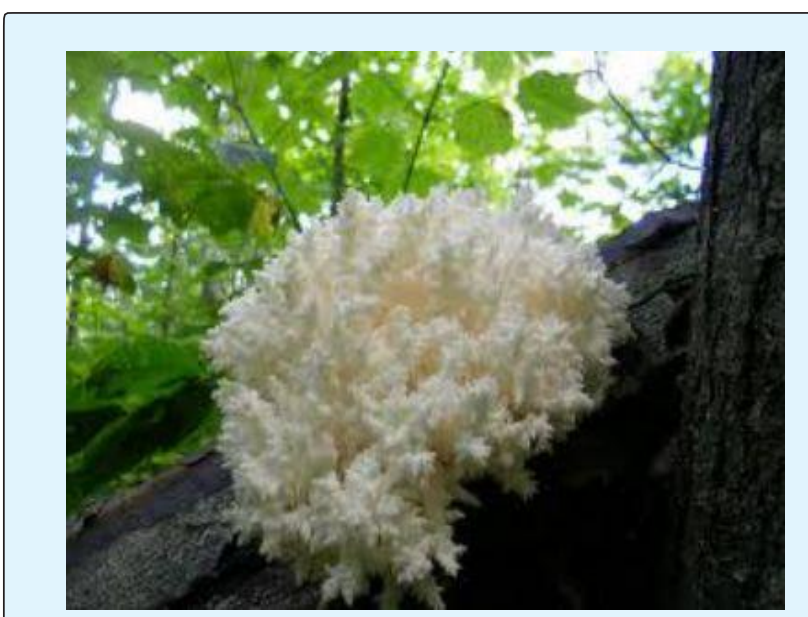

Figure 1: Hericium coralloides in natural conditions.

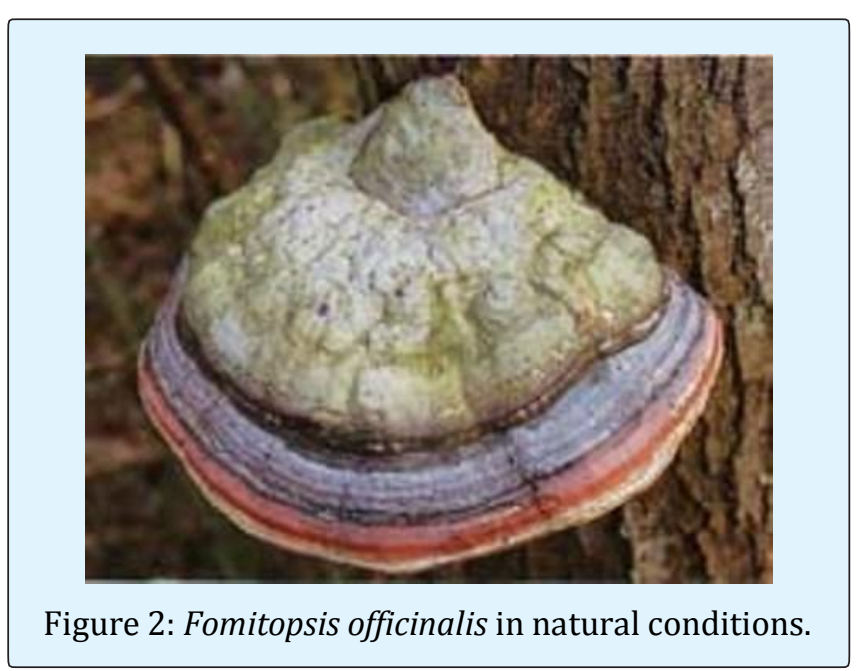




\section{International Journal of Biochemistry \& Physiology}

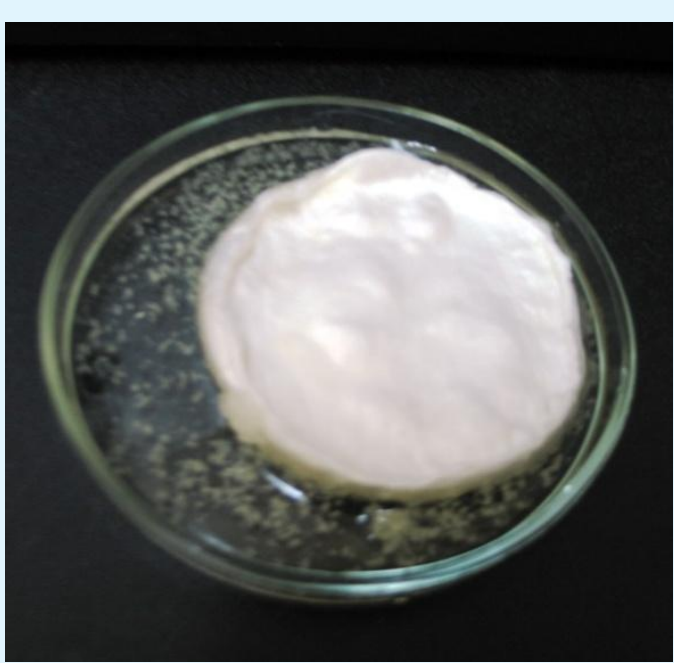

Figure 3: Mycelial culture of $H$. coralloides strain 2332 on agar medium in Petri dish.

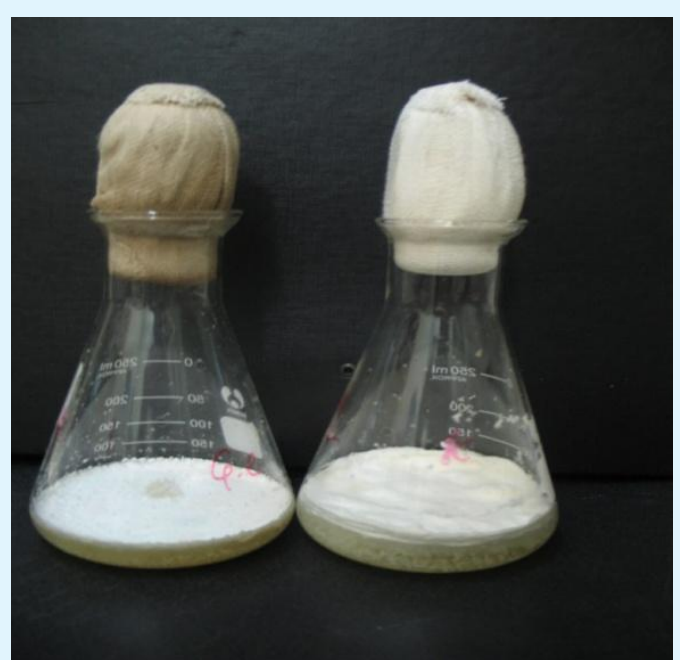

Figure 4: Mycelial culture of $H$. coralloides strain 2332 in liquid nutrient medium in laboratory bottle.

Before the cytokinins analysis mycelial biomass was separated from the culture medium by filtration under vacuum and rinsed twice with $50 \mathrm{ml}$ of potassiumphosphate buffered saline, $\mathrm{pH}$ 6.5.

\section{Cytokinins Analysis}

The samples (10 g of mycelial biomass) were homogenized during 3 min using electrical homogenizer (Mechanika Precyzyjna, Poland) in $80 \%$ methanol solution. Cytokinins were extracted with $80 \%$ methanol $(10 \mathrm{ml} / \mathrm{g})$ and purified as follows: centrifugation $\rightarrow$ fractionation with $\mathrm{n}$-butanol $(1: 1 \mathrm{v} / \mathrm{v}) \rightarrow$ ion-exchange chromatography on Dowex 50Wx8 (Serva, Germany) $\rightarrow$ thin layer chromatography on Silicagel $60 \mathrm{~F}_{254}$ (Merk, Germany). Details of purification procedures were described earlier [21]. Detection and quantification of cytokinins were performed using HPLC-MS system (Agilent 1200, USA). Solid samples were dissolved in $200 \mu \mathrm{l}$ of mobile phase and $5 \mu \mathrm{l}$ aliquot was injected into Agilent Zorbax Eclipse XDB-C18 column (4.6x250 mm, 5 $\mu \mathrm{m})$. The column was eluted with an isocratic solvents system methanol:water:acetic acid (37:62.9:0.1 v/v/v) at a flow rate of $0.5 \mathrm{ml} / \mathrm{min}$ and column temperature of $+30^{\circ} \mathrm{C}$. The fractions eluted were directly passed through mass spectrometer (Agilent 6120 Quadrupole LC/MS) in a combined regime «multi mode» (electrospray and chemical ionization at atmosphere pressure) of positive ionization. Data were analyzed and processed using the software Agilent ChemStation, version B.03.01 on line. Concentrations were calculated on the basis of the peak areas for the endogenous compounds relative to those determined for the internal standards. The example of typical chromatogram is shown in Figure 5.

All experiments conducted in three biological replicates. HPLC-MS analysis was carried out in five analytical replications. The data was processed according to standard methods of variation statistics using Microsoft Excel 2007 program. In the Tables, the average values and standard errors are presented. Values of $\mathrm{P}<0.05$ were considered to be significant.

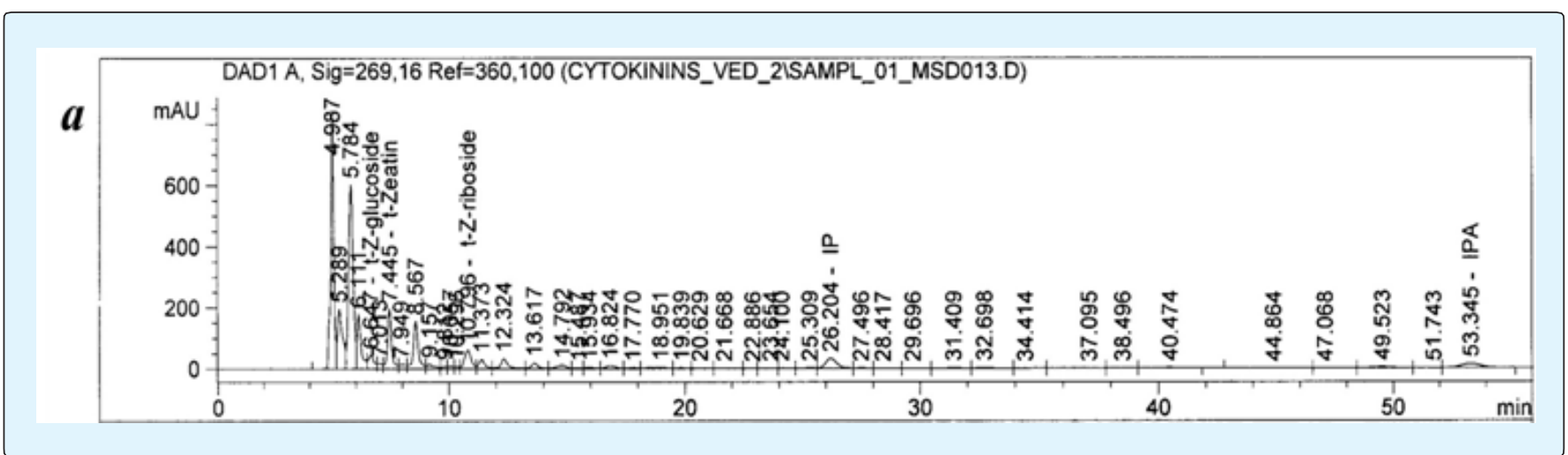




\section{International Journal of Biochemistry \& Physiology}

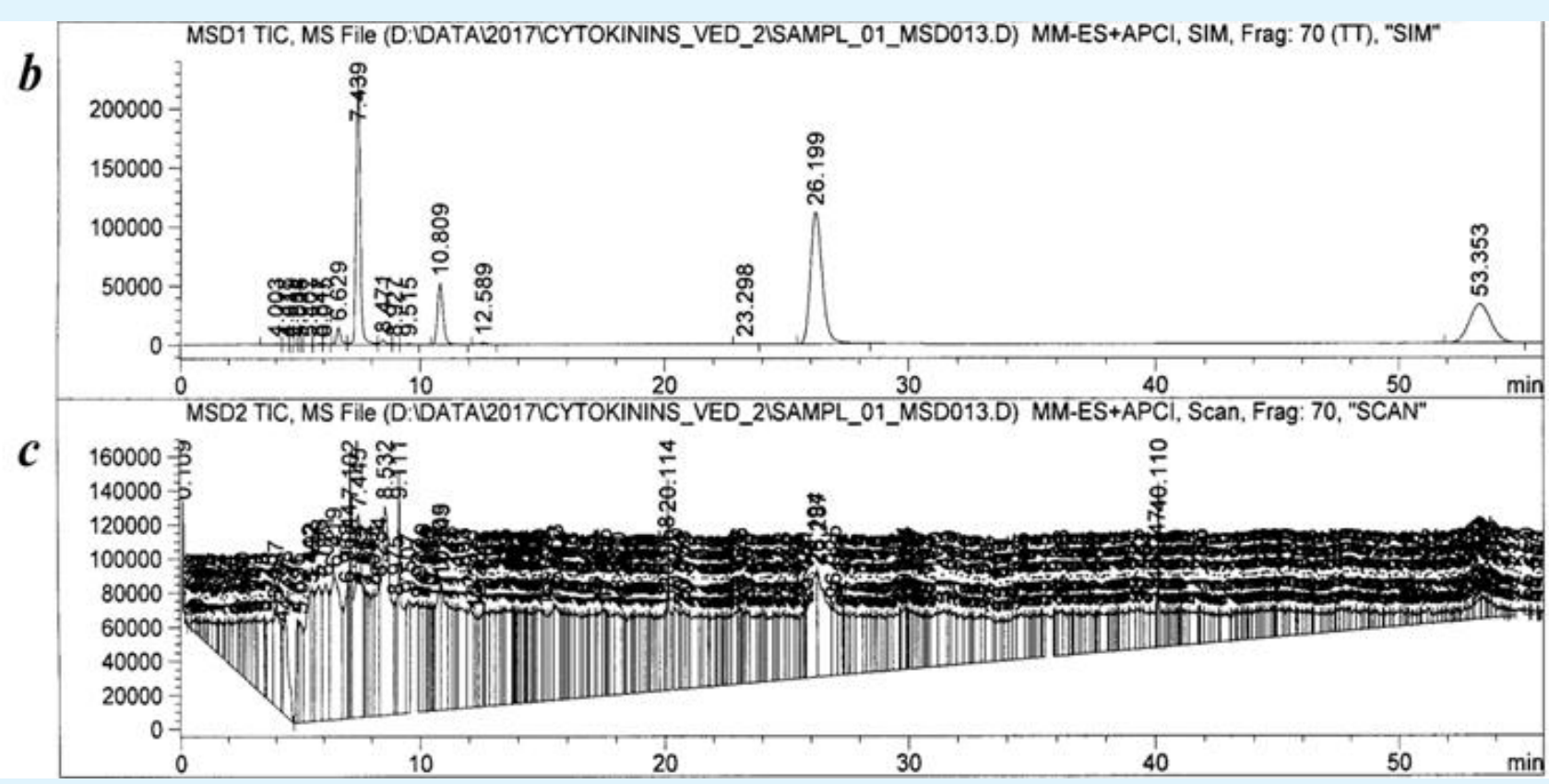

Figure 5: HPLC chromatograms of mycelial biomass sample (H. coralloides strain 2332) obtained using Agilent 1200 chromatographer $(a)$ and mass detector Agilent Quadrupole 6120 LC/MS in regime of individual substances detection SIM $(b)$ and in regime of SCAN mass in range from 200 to $400(c)$.

\section{Results and Discussion}

Studies on the accumulation of dry and fresh matter in the two Basidiomycetes species have demonstrated that there are some differences in $H$. coralloides 2332 and F. officinalis 5004 growth (Figures 6 and 7). So, in the first fungus the dry weight increased seven times and fresh weight - almost fourfold during the first two weeks (between the $14^{\text {th }}$ and $21^{\text {th }}$ days of cultivation), indicating the maximum rate of a mycelial biomass growth (Figure 6).

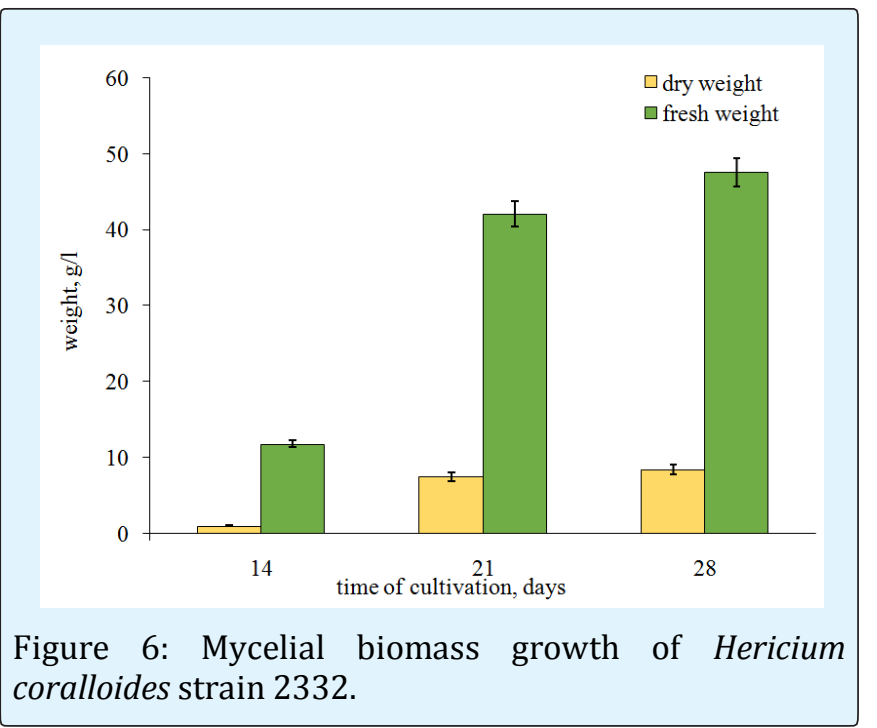

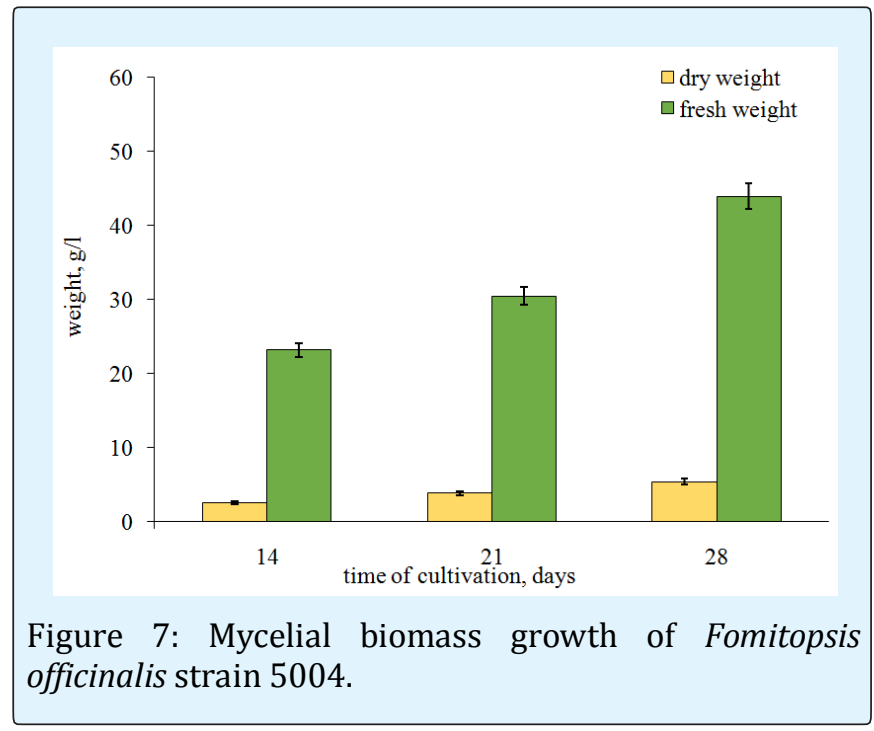

Further, the biomass growth significantly slowed down. In the other studied species, the mycelial biomass weight increased slowly, more evenly and gradually (Figure 7). The fresh weight in $H$. coralloides 2332 was $47.5 \mathrm{~g} / \mathrm{l}$ of nutrient medium by the $28^{\text {th }}$ day of cultivation whereas that of F. officinalis 5004 was $45 \mathrm{~g} / \mathrm{l}$ only by the $40^{\text {th }}$ day. In addition, in F. officinalis 5004 the dry weigh increased very slightly from the $20^{\text {th }}$ till the $40^{\text {th }}$ days of cultivation while in $H$. coralloides 2332 the dry weight increased eightfold during 14 days. 


\section{International Journal of Biochemistry \& Physiology}

Thus, mycelial biomass growth and development in the two studied species - $H$. coralloides 2332 and $F$. officinalis 5004 differ. To elucidate the possible regulatory basis of such difference we have compared the changes in endogenous cytokinins content in these Basidiomycetes.

The presence of both zeatin-type and isopentenyl- type cytokinins was detected in mycelial biomass of investigated mushrooms (Tables 1 and 2). Trans-zeatin, trans-zeatin riboside, zeatin- $O$-glucoside, isopentenyladenosine and isopentenyladenine were determined at all stages of mycelium growth. A similar quantitative composition of the cytokinins pool is characteristic for most plants, where trans-zeatin is usually the most abundant [22].

\begin{tabular}{|c|c|c|c|c|c|c|}
\hline Time of cultivation, days & $t-\mathbf{Z}$ & $t-Z R$ & iPa & iP & ZOG & $\Sigma$ \\
\hline 14 & $2.16 \pm 0.09$ & $0.83 \pm 0.04$ & $0.69 \pm 0.03$ & $1.00 \pm 0.05$ & $0.44 \pm 0.02$ & 5.12 \\
\hline 21 & $0.83 \pm 0.04$ & $0.13 \pm 0.006$ & $0.17 \pm 0.007$ & $0.31 \pm 0.01$ & $0.29 \pm 0.01$ & 1.73 \\
\hline 28 & $0.23 \pm 0.01$ & $0.005 \pm 0.0002$ & $0.04 \pm 0.002$ & $0.03 \pm 0.001$ & $0.29 \pm 0.01$ & 0.595 \\
\hline
\end{tabular}

Table 1: Cytokinins content in mycelial biomass of Hericium coralloides strain 2332, nmol/g FW.

\begin{tabular}{|c|c|c|c|c|c|c|}
\hline Time of cultivation, days & $\boldsymbol{t}$-Z & $\boldsymbol{t}$-ZR & iPa & iP & ZOG & $\boldsymbol{\Sigma}$ \\
\hline 20 & $0.18 \pm 0.009$ & $0.004 \pm 0.0001$ & $0.16 \pm 0.007$ & $0.10 \pm 0.005$ & $0.26 \pm 0.01$ & 0.704 \\
\hline 30 & $0.53 \pm 0.02$ & $0.06 \pm 0.002$ & $0.11 \pm 0.005$ & $0.31 \pm 0.01$ & $0.29 \pm 0.01$ & 1.3 \\
\hline 40 & $0.25 \pm 0.01$ & $0.02 \pm 0.0007$ & $0.03 \pm 0.001$ & $0.03 \pm 0.001$ & $0.20 \pm 0.01$ & 0.53 \\
\hline
\end{tabular}

Table 2: Cytokinins content in mycelial biomass of Fomitopsis officinalis strain 5004, nmol/g FW.

It is known that trans-zeatin is the most active cytokinin in bioassays and it is bounded by at least two receptors with the highest affinity [23]. That is why it is thought to play a predominant role in different aspects of higher plants development. Although this cytokinin was detected earlier in fruit bodies of a large amount of macromycetes species $[16,17,24]$, its importance for mushrooms development regulation is questionable. Nevertheless, trans-zeatin prevalence relative to other cytokinins in mycelial biomass of $H$. coralloides 2332 and $F$. officinalis 5004 indicates a possible functional significance for mycelium growth.

The level of isopentenyladenine was several times lower compared to trans-zeatin (Tables 1 and 2). This cytokinin is produced first via the direct (mevalonate) isopentenyl-dependent pathway of cytokinins biosynthesis, which is shown to operate in fungi and is localized in cytosol and mitochondria [23]. So, isopentenyladenine presence indicates the functioning of such pathway in studied mushrooms. Isopentenyladenine is an unstable product of the mevalonate pathway that is fast hydroxylated to transzeatin by cytochrome P450 monooxygenases [23], that explains its low concentrations.

Considerable amounts of zeatin- $O$-glucoside were detected in mycelial biomass of $H$. coralloides 2332 and F. officinalis 5004 (Tables 1 and 2). This cytokinin conjugate is generally thought to serve as plant inactive storage products, which can easily be activated through hydrolysis by $\beta$-glucosidases. $O$-glucosilation has been shown to prevent cytokinins $N^{6}$-side chain from cleavage with cytokinin oxidase [25]. It can be assumed that excessive amounts of zeatin-type hormones are preserved as zeatin- $O$-glucoside in mycelial biomass. Thus, $O$-conjugate accumulation appears to be a neutralization mechanism for cytokinins hypersynthesis in some mushrooms species.

Ribosylated cytokinin bases (trans-zeatin riboside and isopentenyladenosine) were detected in mycelial biomass at all stages of growth (Tables 1 and 2). In plants, zeatin riboside is regarded as a transport form moving from roots in acropetal direction and is involved in a long-distance signal transmission along stem [26]. Similar functions of this cytokinin in mycelial biomass are impossible for the structural reason. The role of isopentenyladenosine in plants is purely understood. This purine base is present in tRNA of bacteria and eukaryotes and is thought to stabilize codon recognition [27].

The comparison of cytokinins concentration changes in mycelial biomass of $H$. coralloides 2332 and $F$. officinalis 5004 during growth revealed some differences. The highest content of all studied cytokinins was determined in the mycelial biomass of $H$. coralloides 2332 at the initial stage of development. Especially large was the level of active cytokinins forms - trans-zeatin and trans-zeatin riboside by the $14^{\text {th }}$ days of cultivation. It coincides with the highest intensity of growth processes - accumulation of dry and fresh weight (Table 1 and Figure 6). As the growth of $H$. coralloides 2332 biomass slowed down the content of free cytokinins (both zeatin- and isopentenyl-type) 


\section{International Journal of Biochemistry \& Physiology}

decreased manifold. The level of a zeatin- $O$-glucoside also somewhat decreased but it remained rather high even by the $28^{\text {th }}$ day of cultivation. Similar patterns of the active cytokinins dynamics have been observed in many plants. Super high levels of free cytokinins are typical of plant tissues with a high mitotic index whose intensive growth is due to cell division. Growth inhibition involves some decrease in the concentrations of cytokinin active forms and conjugates accumulation [28].

F. officinalis 5004 mycelial biomass showed another pattern of cytokinins dynamics. Insignificant content of active cytokinins was determined at the initial stage of cultivation (Table 2). On the $30^{\text {th }}$ day, the content of all cytokinins, excepting isopentenyladenosine, increased differently. Then the level of all cytokinins reduced, but by the $40^{\text {th }}$ day the concentration of trans-zeatin and trans-zeatin riboside remained still higher than on the $20^{\text {th }}$ day of cultivation. It should be noted that during the period when the content of free cytokinnins increased (the 30th day), no sharp fluctuations in growth characteristics were observed. During the development of $F$. officinalis 5004 mycelial biomass the content of zeatin- $O$-glucoside remained rather high and did not vary. Thus, in contrast to $H$. coralloides $2332, F$. officinalis 5004 did not show any clear correlative relationship between growth intensity and endogenous cytokinin dynamics.

Thus, the results obtained so far does not allow us to make an unambiguous conclusion regarding a possible regulatory role of cytokinins in the development of fungal mycelial biomass. The fact that during mycelium growth the content of all cytokinins changes indicates that these substances are certainly not just metabolites, and their dynamics plays a specific physiological role in the development of fungal biomass. To obtain a more precise answer to the question whether these phytohormones fulfil a regulatory function and which one, further wide-scale studies involving a large range of fungal species are required. Information of this kind will be useful for understanding the hormonal action mechanism in Fungi, for improvement of mushrooms productivity in culture and for a further biotechnological development of new powerful pharmaceutical products.

\section{Conclusions}

The investigation of qualitative composition and dynamics of cytokinin content in mycelial biomass of the two medicinal fungi at the different stages of cultivation demonstrated that in $H$. coralloides 2332 the maximum of trans-zeatin, trans-zeatin riboside, isopentenyladenosine and isopentenyladenine content coincided with the period of the most intensive growth, and biomass development delay is accompanied by a decrease in the level of free cytokinins. Cytokinin dynamics in F. officinalis 5004 did not correlate with a growth intensity. Changes in the cytokinin content during growth were specific for every species and testified to the phytohormone involvement in the regulation of growth and development of mycelial biomass in the studied Basidiomycetes.

\section{References}

1. Werner T, Schmülling T (2009) Cytokinin action in plant development. Curr Opin Plant Biol 12(5): 527 538.

2. Zürcher E, Müller B (2016) Cytokinin synthesis, signaling and function - advances and new insights. Int Rev Cell Mol Biol 324: 1-38.

3. Persson BC, Esberg B, Ólafsen Ó, Björk GR (1994) Synthesis and function of isopentenyl adenosine derivatives in tRNA. Biochimie 76(12): 1152-1160.

4. Kenrick P, Crane PR (1997) The origin and early evolution of plants on land. Nature 389: 33-39.

5. Chanclud E, Morel JB (2016) Plant hormones: a fungal point of view. Mol Plant Pathol 17(8): 12891297.

6. Walters DR, McRoberts N (2006) Plants and biotrophs: a pivotal role for cytokinins? Trends Plant Sci 11(12): 581-586.

7. Grant MR, Jones JD (2009) Hormone (dis)harmony moulds plant health and disease. Science 324(5928): 750-752.

8. Hinsch J, Vrabka J, Oeser B, Novák O, Galuszka P, et al. (2015) De novo biosynthesis of cytokinins in the biotrophic fungus Claviceps purpurea. Environmental Microbiology 17(8): 2935-2951.

9. Paul D, Guha AK, Chatterjee BP (1994) Effect of plant growth hormones on Kluyveromyces fragilis grown on deproteinized whey. Biochem Arch 10: 277-283.

10. Chatterjee S, Chatterjee BP, Guha AK (2008) Enhancement of growth and chitosan production by Rhizopus oryzae in whey medium by plant growth hormones. Int J Biol Macromol 42(2):120-126.

11. Safaei Z, Karimi K, Golkar P, Zamani A (2015) Effects of plant hormones on Mucor indicus frowth and chitosan and ethanol production. Int J Mol Sci 16(7): 16683-16694. 


\section{International Journal of Biochemistry \& Physiology}

12. Ramachela K, Sihlangu SM, Moral MT (2016) Effect of various hormonal treated plant substrates on development and yield of Pleurotus ostreatus. Cogent Food \& Agriculture 2(1): 1276510.

13. Mukhopadhyay R, Chatterjee S, Chatterjee BP, Guha AK (2005) Enhancement of biomass production of edible mushroom Pleurotus sajor-caju grown in whey by plant growth hormones. Process Biochemistry 40(3-4): 1241-1244.

14. Guha AK, Banerjee AB (1974) Effect of indole-3acetic acid and kinetin on submerged growth of Agaricus campestris. Acta Microbiol Pol B 6(3): 133134.

15. Kovač M, Žel J (1995) The effect of aluminum on cytokinins in the mycelia of Amanita muscaria. J Plant Growth Regul 14(3): 117-120.

16. Türker $M$, Demirel $K$, Uzun $Y$, Battal $P$, Tileklioğlu $B$ (2005) Determination of phytohormones level in some dried and fresh macrofungi taxa. PhytonAnnales rei Botanicae 45: 145-157.

17. Morrison EN, Knowles S, Hayward A, Thorn RG, Saville BJ, et al. (2015) Detection of phytohormones in temperate forest fungi predicts consistent abscisic acid production and a common pathway for cytokinin biosynthesis. Mycologia 107(2): 245-257.

18. Rypacek V, Sladky Z (1973) Relation between the level of endogenous growth regulators and the differentiation of the fungus Lentinus tigrinus studied in a synthetic medium. Biologia Plantarum 15(1): 20-26.

19. Wasser SP (2014) Medicinal mushroom science: Current perspectives, advances, evidences, and challenges. Biomed J 37(6): 345-356.
20. Bisko NA, Lomberg ML, Mytropolska $\mathrm{NYu}$ Mykchaylova OB (2016) The IBK Mushroom Culture Collection. Kyiv: M.G. Kholodny Institute of Botany, National Academy of Sciences of Ukraine, Alterpres pp: 215.

21. Vedenicheva NP, Al-Maali GA, Mytropolska NYu, Mykhaylova OB, Bisko NA, et al. (2016) Endogenous cytokinins in medicinal basidiomycetes mycelial biomass. Biotechnologia Acta 9(1): 55-63.

22. Kieber JJ, Schaller GE (2014) Cytokinins. The Arabidopsis Book 11: e0168.

23. Frébort I, Kowalska M, Hluska T, Frébortová J, Galuszka P (2011) Evolution of cytokinin biosynthesis and degradation. J Exp Bot 62(8): 2431-2452.

24. Özcan B (2001) GA3, ABA and cytokinin production by Lentinus tigrinus and Laetiporus sulphureus fungi cultured in the medium of olive oil mill waste. Turk J Biol 25(4): 453-462.

25. Mok DWS, Mok MC (2001) Cytokinin metabolism and action. Annu Rev Plant Physiol Plant Mol Biol 52: 89-118.

26. Romanov GA (2009) How do cytokinins affect the cell? Russian J Plant Physiol 56(2): 268-290.

27. Schweizer U, Bohleber S, Fradejas-Villar N (2017) The modified base isopentenyladenosine and its derivatives in tRNA. RNA Biol 14(9): 1197-1208.

28. Jameson PE, Song J (2016) Cytokinin: a key driver of seed yield. J Exp Bot 67(3): 593-606. 